\title{
BALANCED SCORECARD: ESTUDO BIBLIOMÉTRICO DA PRODUÇÃO CIENTÍFICA BRASILEIRA NO PERÍODO 2002-2012
}

\author{
BALANCED SCORECARD: BIBLIOMETRIC STUDY OF BRAZILIAN \\ SCIENTIFIC PRODUCTION IN THE PERIOD 2002-2012
}

\author{
Veronica Eberle de Almeida², Romualdo Douglas Colauto 3 , \\ Jacqueline Veneroso Alves da Cunha ${ }^{4}$ e Claudineia Kudlawicz ${ }^{5}$
}

Recebido em: 18/09/2013

Aprovado em: 16/12/2013

\section{RESUMO}

A mensuração dos resultados é cada vez mais necessária em um mundo permeado pela mudança e pela competitividade. A fim de possibilitar um melhor acompanhamento do desempenho, as organizações utilizam-se de indicadores, que, na grande maioria, limitam-se às análises estritamente financeiras. Neste contexto, surgiu a metodologia denominada Balanced Scorecard (BSC), proposta por Kaplan e Norton. O objetivo deste estudo é analisar a produção científica relacionada ao BSC veiculada por congressos e periódicos brasileiros entre o período de 2002 e 2012, descrevendo características quantitativas e qualitativas dessa produção. Verificou-se que este tema é bastante pesquisado no universo acadêmico, tendo sido observada a ocorrência do efeito Mateus. Palavras-chave: Balanced Scorecard; Bibliometria; Produção Científica Brasileira.

\section{Introdução}

A preocupação das organizações cada vez mais tem se voltado para o ambiente competitivo e para a otimização dos recursos no processo produtivo, motivo pelo qual se sentem pressionadas a promover mudanças em suas estruturas e estratégias. Desse modo, a mudança organizacional tem sido incorporada na rotina das organizações e não pode mais ser considerada como um fenômeno excepcional (MACHADO-DA-SIL-

\begin{abstract}
The measurement of outcomes is increasingly necessary in a world permeated by change and competitiveness. In order to enable better monitoring of performance, organizations make use of indicators for this purpose which, in most cases, are strictly limited to financial analysis. BSC proposed by Kaplan and Norton - in this context the methodology called Balanced Scorecard has emerged. The aim of this study is to analyze the scientific production related to BSC conveyed by Congress and Brazilian journals between the years 2002 and 2012, describing quantitative and qualitative characteristics of these productions. It was found that this topic is widely researched in academia, the occurrence of the Matthew effect was observed.

Keywords: Balanced Scorecard; Bibliometrics; Brazilian Scientific Production.
\end{abstract}

VA; FONSECA; FERNANDES, 1999). O desafio provém da globalização, da competitividade, da necessidade de desenvolvimento sustentável, do fortalecimento de novas potências mundiais e de tantos outros motivos que fazem com que organizações tenham de se adequar ao novo contexto e aos novos padrões impostos a fim de evitarem o risco de serem acometidas pela obsolescência organizacional (SALES; SILVA, 2007).

Neste contexto, a mensuração dos resultados é essencial para a gestão

\footnotetext{
${ }^{1}$ Artigo apresentado no XV Congresso Latino-Iberoamericano de Gestão de Tecnologia. Porto, 27 a 31 de Outubro de 2013.

${ }^{2}$ Doutoranda em Administração pela Universidade Positivo, Brasil. Administradora na Companhia Paranaense de Energia (COPEL). E-mail: veronica. eberle $@$ gmail.com. eberle@gmail.com.

${ }^{3}$ Pós-Doutorando da Faculdade de Economia e Administração da Universidade de São Paulo (FEA/USP), Brasil. Professor da Universidade Federal do Paraná (UFPR). E-mail: rdcolauto.ufpr@gmail.com.

${ }^{4}$ Doutora em Ciências Contábeis pela Universidade de São Paulo (USP), Brasil. Professora adjunta da Faculdade de Ciências Econômicas da Universidade Federal de Minas Gerais (UFMG), Brasil. Doutora em Ciências Contábeis. E-mail: jvacbr@terra.com.br.
}

${ }_{5}^{5}$ Doutoranda em Administração pela Pontifícia Universidade Católica do Paraná (PUC-PR), Brasil. E-mail: claudineia09@yahoo.com.br. 
organizacional, pois confere efetividade às metas e aos objetivos estabelecidos, auxiliando o processo decisório no que se refere a ajustes e medidas que precisam ser tomadas (KAPLAN, 2012). A necessidade de melhorar o desempenho organizacional e aumentar as vantagens competitivas tem exigido o desenvolvimento de ferramentas gerenciais para subsidiar gestores no processo de tomada de decisão (HEINRICH, 2010). Diante disso, surgiu na década de 90 o Balanced Scorecard (BSC), proposto por Robert Kaplan e David Norton, em virtude da insuficiência da utilização estrita de indicadores financeiros para a gestão organizacional. Essa ferramenta se mostrou uma alternativa para melhorar a gestão e o acompanhamento dos resultados da organização, uma vez que é focada no planejamento estratégico e no desempenho (OLIVEIRA et al., 2012), sendo, portanto, uma das abordagens que frequentemente é sugerida para melhorar o desempenho organizacional (COAD, 1999).

Olve, Roy e Wetter (2001, p. 13) definem o BSC como um elemento de um sistema relacionado com o controle estratégico e uma resposta às críticas que são dirigidas ao gerenciamento voltado à utilização de medidas estritamente financeiras, uma vez que estas expressam resultados acerca de eventos que já ocorreram e sobre os quais as ações já não surtem efeitos. Kaplan e Norton $(1997$, p. 8) asseveram que o BSC "complementa as medidas financeiras do desempenho passado com medidas dos vetores que impulsionam o desempenho futuro", de modo que seus objetivos e suas medidas derivam da visão e da estratégia da empresa. De acordo com Picoli, Abib e Fonseca (2012), o BSC foi considerado apropriado e aceito tanto no ambiente empresarial quanto no ambiente acadêmico, proporcionando a união entre teoria e prática. Desde então, pesquisas e publicações inerentes a este tema se estenderam, dando origem à produções sobre essa metodolo- gia nas áreas de Administração, Economia e Ciências Contábeis.

A carência de pesquisas que relatem a forma como está sendo tratado o BSC no Brasil originou o presente estudo. A percepção dos motivos que levaram organizações a adotar o BSC, a maneira como isso ocorreu e o período em que se deu tem por objetivo auxiliar no entendimento da ocorrência de um possível modismo gerencial nas organizações. Assim, a verificação dos estudos existentes no período de 2002 a 2012 pode auxiliar na compreensão e na comprovação desse fato no cenário nacional.

Diante dessa perspectiva, este estudo pretende analisar, sob a ótica da bibliometria, a produção científica relacionada ao BSC veiculada por congressos e periódicos brasileiros entre os anos de 2002 e 2012, descrevendo características tanto quantitativas quanto qualitativas das produções levantadas, a fim de compreender as razões que levaram organizações a adotar a ferramenta no cenário brasileiro.

$\mathrm{Na}$ literatura nacional, é possível verificar alguns estudos correlatos, tais como o conduzido por Picoli, Abib e Fonseca (2012), que se propuseram a mapear as características das produções acadêmicas acerca do BSC procedentes dos Encontros Anuais da Associação Nacional dos Programas de Pós-Graduação em Administração (EnANPADs) nos anos de 2001 a 2011, verificando a existência de uma consonância entre o BSC e o campo de estratégia, bem como analisando a maneira como os estudos acerca dessa temática têm sido desenvolvidos. Catapan et al. (2012) analisaram bibliometricamente a produção científica sobre o BSC veiculada pelos periódicos classificados como B1, B2 e B3 no Sistemas Qualis, da CAPES, com o objetivo de identificar as tendências e publicações entre o período de 2001 e 2011. Os autores concluíram que os artigos de cunho teórico, os quais representaram $54 \%$, pre- 
dominaram em relação aos artigos empíricos. Além disso, mais de $70 \%$ dos trabalhos foram escritos por associação entre dois pesquisadores e $21 \%$ foram conduzidos por três autores. Tais estudos se propuseram a apresentar dados de cunho estritamente bibliométrico, não se aprofundando no conteúdo dos artigos levantados.

O presente trabalho está estruturado da seguinte maneira: seguida desta introdução, está o referencial teórico relacionado ao Balanced Scorecard, apresentando breve incursão teórica sobre o assunto; na sequência, é apresentada a metodologia, que contém as orientações deste estudo para o cumprimento do objetivo proposto, seguida da apresentação e análise dos dados e, por fim, das considerações finais.

\section{Balanced scorecard}

Gomes e Salas (2001) afirmam que a eficácia de um controle de gestão parte do princípio de que os esforços alocados em uma atividade, caso os resultados projetados como objetivo pela organização não forem alcançados, podem ser redirecionados. Assim, esse processo de controle demanda a obtenção de informações que possibilitem a formulação de diretrizes e a mensuração do resultado. De acordo com Santana (2010), o tipo de informação está relacionado de forma direta com o processo de escolha dos instrumentos gerenciais e com a abordagem contextual e organizacional do processo de gestão. Segundo Gonçalves (2002 apud ALMEIDA; MARÇAL; KOVALESKI, 2004, p. 1188), a característica essencial de uma organização é a capacidade de aplicar, de maneira efetiva, seus indicadores para a medição de seu desempenho, de modo a proporcionar maior conhecimento de seus processos e permitir avaliação contínua da eficiência de seus processos e pessoas. Neste contexto, as metodologias de avaliação de desempenho constituem importante ferramenta para o acompanhamento do desenvolvimento e da evolução da organização. Neely et al. (1996) conceituam o indicador de desempenho como um meio de a organização quantificar a eficiência e/ ou a eficácia de uma tomada de decisão, permitindo, portanto, que as organizações saibam o que estão fazendo e quais são os resultados de suas ações.

O BSC foi desenvolvido, inicialmente, como um sistema de mensuração de desempenho e, depois, foi alterado para um sistema de gestão estratégica (KALLÁS, 2003). O BSC consiste, assim, em uma metodologia que visa à avaliação, medição e otimização do desempenho organizacional por meio de um conjunto de medidas balanceadas de desempenho que consideram indicadores financeiros e não financeiros. Essas medidas são agrupadas em quatro dimensões: (1) financeira, (2) cliente, (3) processos internos e (4) aprendizado e conhecimento.

Alguns modelos adotam somente as medidas financeiras para gerir o desempenho. No entanto, Banker, Potter e Srinivasan (2000) defendem que as medidas não financeiras são melhores indicadores de medidas de desempenho futuro do que as medidas financeiras, pois auxiliam os administradores a focarem suas ações nas perspectivas de longo prazo. Além disso, Veen-Dirks (2010) afirma que as medidas de desempenho não financeiro facilitam a tomada de decisão, enquanto que as medidas de desempenho financeiro podem, relativamente, influenciar a tomada de decisão no contexto da utilização das medidas de desempenho para avaliação e recompensa dos administradores.

Kaplan e Norton (2000) explicitam que o aprendizado e o crescimento consistem em aspectos-chave para a organização, pois formam a base para a melhoria da qualidade e da inovação tendo em vista a alta competitividade existente. Os autores comentam, ainda, que, para a implantação da metodologia $\mathrm{BSC}$, é preciso que a estratégia da 
empresa seja traduzida em iniciativas e objetivos específicos, de maneira que se obtenham respostas às perguntas sobre onde e como se quer chegar. Além dessa etapa fundamental, são necessárias a coleta de dados, a garantia de que o fluxo de informações seja constante e a avaliação da direção pela qual a empresa caminha para verificar se a direção que havia sido traçada está sendo seguida. São sete as etapas pelas quais a organização deve passar: (1) Identificação da visão, (2) Identificação da estratégia, (3) Identificação dos fatores críticos de sucesso, (4) Seleção de indicadores, (5) Avaliação, (6) Criação dos planos de ação e (7) Acompanhamento e gestão. Dessa forma, após a implantação do BSC, a organização poderá se beneficiar com a visão sistematizada de seu desempenho e desenvolver uma cultura de aprendizagem e melhoria contínua. Além disso, será possível atribuir incentivos ao desempenho individual dos colaboradores, os quais contribuem para os resultados obtidos pela organização.

Attadia, Canevarolo e Martins (2003) estabelecem uma análise crítica acerca do BSC baseada em três fatores para a avaliação: conceitual, estrutural e gerencial. A crítica no nível conceitual está centrada no fato de que o BSC foi concebido a partir de um contexto prescritivo, o que o limitou enquanto sistema de gestão de desempenho, pois o empreendedorismo, a influência da cultura, a liderança, o poder etc. não são considerados. Sob o nível estrutural, recai a crítica de que são encontradas falhas em sua configuração, como perspectivas, balanceamento de medidas de desempenho, relações causa-efeito e mapa estratégico, por exemplo. Já no nível gerencial, a implantação efetiva do BSC esbarra em itens como a tradução da visão (uma vez que se trata de uma ferramenta para implantação e não para formulação), o desdobramento vertical e horizontal da estratégia (em seus aspectos comunicativos e de ligação), a falta de orientação quanto à integração do BSC ao orçamento etc. No entanto, mesmo com as críticas feitas por Attadia, Canevarolo e Martins (2003), é válido ressaltar que o BSC utiliza medidas balanceadas e integradas para o monitoramento do alcance dos objetivos estratégicos traçados pela organização.

\section{Método}

A metodologia desempenha papel fundamental na condução de uma pesquisa, uma vez que são esclarecidas aos leitores as decisões tomadas pelos autores, que estão calcados em princípios de cientificidade (THIOLLENT, 1997). De caráter descritivo, a presente pesquisa tem por objetivo analisar a produção científica veiculada em congressos e periódicos brasileiros sobre o Balanced Scorecard entre os anos 2002 e 2012, a fim de descrever suas características quantitativas e qualitativas, bem como compreender as razões que levaram organizações a adotar a ferramenta no cenário brasileiro.

Para a condução desta pesquisa, utilizaram-se os conceitos preconizados pela bibliometria, a qual, de acordo com Tague-Sutcliffe (1992), consiste no estudo dos aspectos quantitativos da produção, da disseminação e do uso da informação registrada. Okubo (1997) afirma que a bibliometria pode ser considerada como uma ferramenta que possibilita observar o estado da ciência e da tecnologia por meio da utilização da produção geral da literatura científica. Apesar de esta pesquisa se utilizar da bibliometria, ela não se restringe a descrever quantitativamente os seus achados, pois analisa qualitativamente alguns aspectos da produção levantada, incluindo metodologia, emprego do BSC como variável dependente ou independente, existência da utilização de alguma teoria como base para a condução das pesquisas e relação com outros conceitos e definições que tenham sido usados. $\mathrm{O}$ aprofundamento da análise qualitativa buscará, também, compreender as motivações para que organizações 
tenham adotado a ferramenta em sua administração, a maneira que esta ação ocorreu e o período em que se deu.

Para operacionalização deste estudo, estão sendo considerados os três maiores congressos brasileiros na área da contabilidade: (1) Congresso da Associação Nacional dos Programas de Pós-Graduação em Ciências Contábeis (Anpcont), (2) Congresso USP de Controladoria e Contabilidade e (3) Encontro Nacional da Associação Nacional de Pós-Graduação e Pesquisa em Administração (EnANPAD). Além desses eventos, considerados como meio propício para discussão em nível acadêmico, foram analisados, também, todos os periódicos nacionais que publicam conteúdo de Controle Gerencial classificados pelo sistema Qualis da CAPES no período de 2002 a 2012. O Quadro 1 apresenta os congressos e periódicos analisados, suas respectivas classificações de acordo com o sistema brasileiro Qualis, o período disponível para análise (tendo em vista que alguns destes não apresentaram publicação desde o ano de 2002) e o total de artigos analisados.

\begin{tabular}{|c|c|c|c|}
\hline Congresso / Periódico & $\begin{array}{l}\text { Classificação } \\
\text { Qualis 2012 }\end{array}$ & $\begin{array}{l}\text { Período de } \\
\text { análise }\end{array}$ & $\begin{array}{c}\text { Total de } \\
\text { artigos } \\
\text { analisados }\end{array}$ \\
\hline $\begin{array}{l}\text { Congresso da Associação Nacional dos } \\
\text { Programas de Pós-Graduação em Ciências } \\
\text { Contábeis (Anpcont) }\end{array}$ & A & 2007 a 2012 & 136 \\
\hline $\begin{array}{l}\text { Congresso USP de Controladoria e Con- } \\
\text { tabilidade }\end{array}$ & A & 2002 a 2012 & 434 \\
\hline $\begin{array}{l}\text { Encontro Nacional da Associação Nacio- } \\
\text { nal de Pós-Graduação e Pesquisa em Ad- } \\
\text { ministração (EnAnpad) }\end{array}$ & A & 2002 a 2012 & 493 \\
\hline Revista Brazilian Business Review & $\mathrm{A} 2$ & 2004 a 2012 & 153 \\
\hline Revista Contabilidade \& Controladoria & B3 & 2009 a 2012 & 75 \\
\hline Revista Contabilidade e Finanças & A2 & 2002 a 2012 & 276 \\
\hline Revista Contabilidade e Organizações & B1 & 2007 a 2012 & 129 \\
\hline Revista Contabilidade Vista \& Revista & B1 & 2002 a 2011 & 226 \\
\hline $\begin{array}{l}\text { Revista Contabilidade, Gestão e Gover- } \\
\text { nança }\end{array}$ & B2 & 2002 a 2012 & 167 \\
\hline Revista Contemporânea de Contabilidade & B3 & 2004 a 2012 & 133 \\
\hline Revista de Administração Contemporânea & $\mathrm{A} 2$ & 2002 a 2012 & 473 \\
\hline $\begin{array}{l}\text { Revista de Administração, Contabilidade } \\
\text { e Economia }\end{array}$ & B4 & 2007 a 2012 & 83 \\
\hline $\begin{array}{l}\text { Revista de Educação e Pesquisa em Con- } \\
\text { tabilidade }\end{array}$ & B3 & 2007 a 2012 & 120 \\
\hline Revista de Informação Contábil & B3 & 2007 a 2012 & 119 \\
\hline Revista Enfoque & B2 & 2005 a 2012 & 121 \\
\hline Revista Organizações e Sociedade & $\mathrm{A} 2$ & 2002 a 2012 & 404 \\
\hline Revista Registro Contábil & B3 & 2010 a 2012 & 38 \\
\hline Revista Universo Contábil & B1 & 2005 a 2012 & 245 \\
\hline \multicolumn{3}{|l|}{ Total } & 3825 \\
\hline
\end{tabular}

Quadro 1 - Relação de congressos e periódicos analisados

Fonte: dados da pesquisa. 
No total, foram analisados 3825 artigos, dos quais 1063 são provenientes apenas de congressos, o que representa quase $30 \%$ do total. A seleção dos congressos e periódicos para análise foi realizada por meio da acessibilidade e conveniência, uma vez que os autores já possuíam os trabalhos salvos em seu computador pessoal. Cabe complementar que, para análise dos artigos veiculados pelos congressos e pelo encontro da ANPAD, foram consideradas as seguintes áreas temáticas para download dos trabalhos junto aos sites dos congressos (Quadro 2):

\begin{tabular}{|c|c|c|}
\hline Congresso & Ano(s) & Área Temática \\
\hline Anpcont & 2007 a 2012 & Controladoria e Contabilidade Gerencial \\
\hline Congresso USP & 2002 a 2003 & Todas as áreas \\
\hline Congresso USP & 2004 a 2012 & Controladoria e Contabilidade Gerencial \\
\hline EnAnpad & 2002 a 2004 & Contabilidade e Controle Gerencial \\
\hline EnAnpad & 2005 a 2006 & Contabilidade Gerencial e Controladoria \\
\hline EnAnpad & 2007 a 2008 & Contabilidade Gerencial \\
\hline EnAnpad & 2009 a 2012 & Controladoria e Contabilidade Gerencial \\
\hline
\end{tabular}

Quadro 2 - Áreas temáticas analisadas em cada congresso

Fonte: dados da pesquisa.

As edições dos anos de 2002 e 2003 do Congresso USP foram analisadas em sua totalidade, já que os trabalhos não eram divididos em áreas temáticas. A seleção dos artigos relacionados ao BSC para análise foi feita por meio da leitura do título e das palavras-chave de cada um dos 3825 artigos levantados. Quando o artigo não possuía indicação das palavras-chave, era realizada a leitura do resumo e/ou busca por palavras como "balanced", "scorecard" e "bsc". Apenas nos casos em que estas palavras apareciam no corpo do resumo é que o artigo era selecionado. Finalizada essa etapa, foi composto o banco de dados para esta pesquisa com um total de 68 trabalhos selecionados, o que corresponde a quase $2 \%$ do total de artigos levantados.

Para tabular os dados, utilizou-se como critério a leitura flutuante dos 68 artigos para identificar a quantidade e o nome de autores, o objetivo do estudo, a metodologia utilizada, a categorização para fins de agrupamento de pesquisas correlatas, a percepção do BSC como variável dependente ou independente e a identificação da utilização de Teoria de Base para a condução de cada pesquisa. No tópico seguinte, são apresentados os dados e sua respectiva análise.

\section{Apresentação e discussão dos dados}

Dos 68 artigos selecionados para análise, $60 \%$ se referem a trabalhos veiculados em congressos e $40 \%$ a trabalhos publicados em periódicos. O Gráfico 1 apresenta a quantidade de artigos que tratam do BSC publicados nos anos de 2002 a 2012. Vale destacar a oscilação entre o número de trabalhos publicados em cada ano, com a predominância da veiculação de artigos por meio de congressos. 


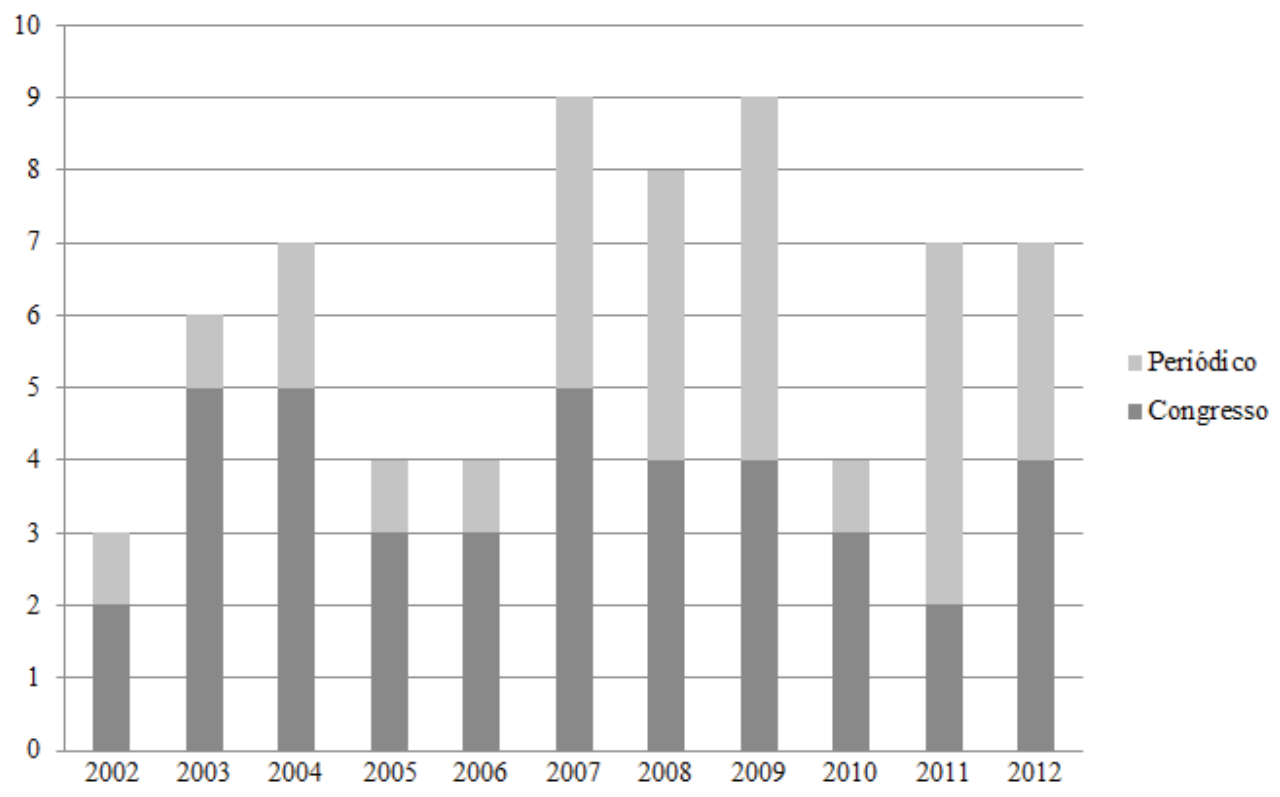

Gráfico 1 - Oscilação no número de artigos publicados relacionados ao BSC por ano Fonte: dados da pesquisa.

O Gráfico 2 apresenta a quantidade de artigos publicados por congresso e por periódico. É necessário destacar o número de publicações por meio da apresentação de trabalhos em congressos. No que se refere aos periódicos, chama atenção a Revista Universo Contábil, com cinco publicações sobre o assunto, acompanhada das revistas Contabilidade e Finanças, Contabilidade
Vista e Revista e, também, a Revista Contemporânea de Contabilidade. Nota-se que a Revista Brazilian Business Review, a Revista de Educação e Pesquisa em Contabilidade, a Revista Organizações e Sociedade e a Revista Registro Contábil não apresentaram nenhuma publicação no período analisado, não tendo sido identificadas razões que pudessem justificar tal fato.

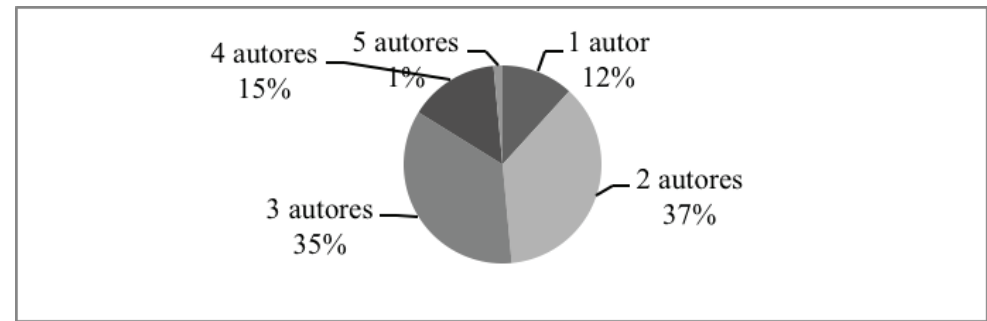

Gráfico 2 - Quantidade de publicação por congresso e por periódico Fonte: dados da pesquisa. 
O Gráfico 3 apresenta a proporção do número de autores por artigo. Nota-se que predominam as pesquisas desenvolvidas por dois e três autores (37\% e 35\% respectivamente), seguidas dos estudos conduzidos por quatro autores (15\%) e por um autor (12\%). Apenas um estudo (o qual representa 1\%) foi conduzido por um conjunto de cinco autores dentre os artigos analisados nesta pesquisa. Esse resultado está de acordo com os achados de Picoli, Abib e Fonseca (2012, p. 140) no que se refere à "tendência de publicações em duplas e trios".

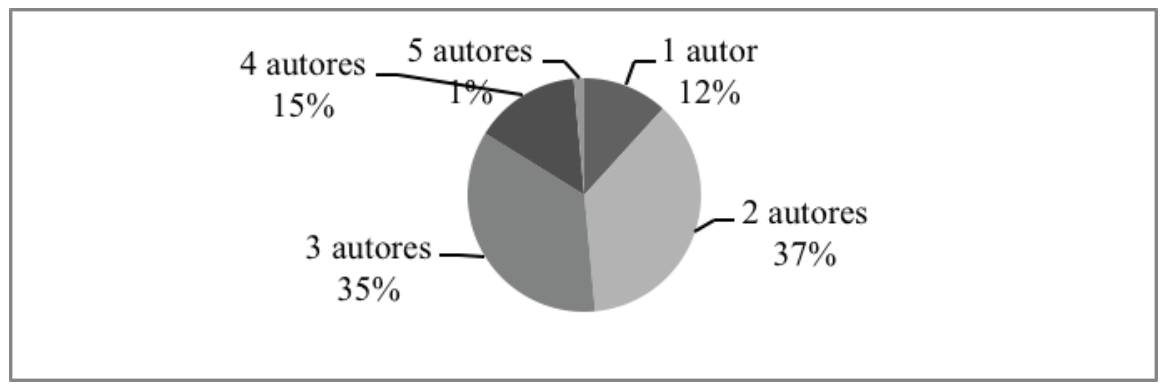

Gráfico 3 - Artigos conforme número de autores Fonte: dados da pesquisa.

Da análise dos dados, foi possível depreender que 103 pesquisadores publicaram, no período considerado, apenas um trabalho referente ao BSC. Outras 25 pessoas publicaram dois trabalhos e seis pessoas publicaram três trabalhos. Uma autora, Vera Maria Rodrigues Ponte, destacou-se pela publicação de quatro artigos sobre o BSC. Diante disso, pode-se fazer alusão ao efeito Mateus, sobre o qual Merton (1968) diz que, àqueles que mais possuem, mais lhes será dado e, aos que menos têm, até o que tiverem lhes será retirado. A ideia desta relação está no fato, verificado nesta pesquisa, de poucos autores publicarem muito e muitos publicarem pouco, em uma relação inversamente proporcional. O Gráfico 4 apresenta a proporção entre o número de publicações por autor resultante desta pesquisa, em que é possível perceber a importância dos trabalhos publicados por autores que tiveram apenas um estudo veiculado em congresso ou periódico.

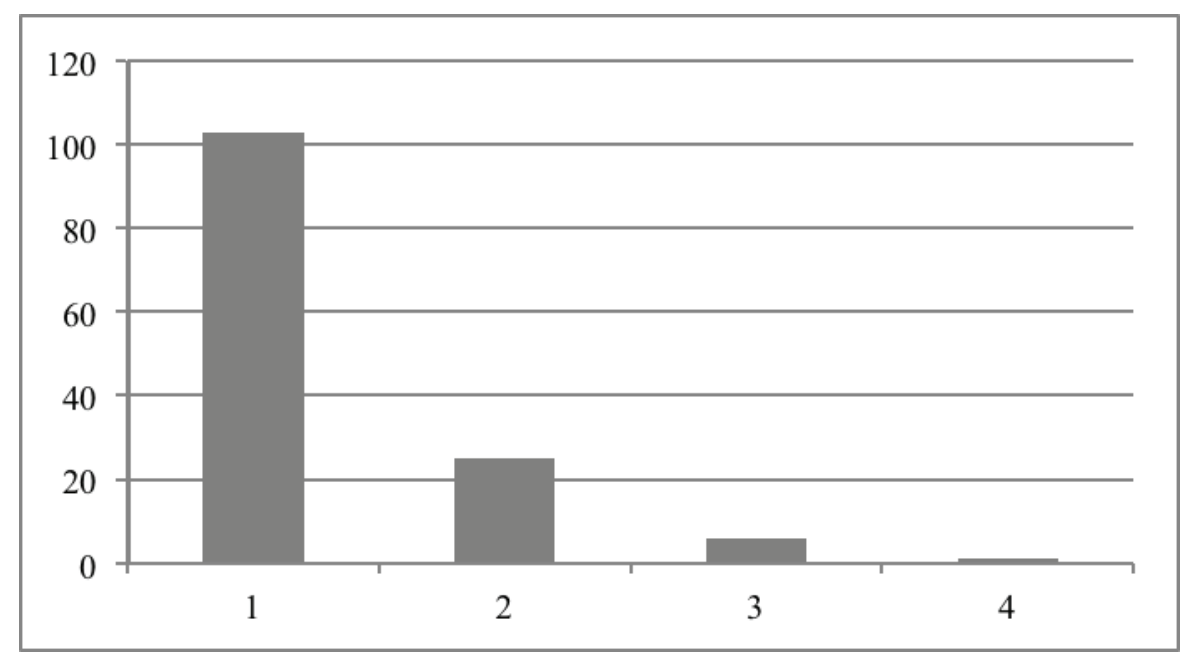

Gráfico 4 - Proporção do número de publicações por autor Fonte: dados da pesquisa. 
A análise dos artigos permitiu, também, verificar qual a metodologia mais utilizada. $\mathrm{O}$ estudo de caso aparece em $37 \%$ dos artigos, corroborando os resultados obtidos por Picoli, Abib e Fonseca (2012), seguido da pesquisa empírica $(24 \%)$ e do estudo de caso múltiplo $(16 \%)$. As demais técnicas pesquisa-ação $(12 \%)$, pesquisa teórico-empírica $(9 \%)$ e bibliometria (1\%) também foram identificadas, mas com menor representatividade. Cabe ressaltar que duas das oito pesquisas que foram conduzidas como pesquisa-ação utilizaram a Técnica Delphi, que, segundo Martino
(1993), é um tipo de pesquisa qualitativa por meio da qual se busca o consenso de opiniões entre os membros de um grupo com relação a eventos futuros, sendo recomendada para situações em que não se dispõe de dados quantitativos ou em que os dados não possam ser projetados para o futuro com segurança, em virtude de mudanças estruturais nos fatores determinantes das tendências futuras. Dos trabalhos analisados, apenas em um não foi possível identificar a metodologia utilizada. O Gráfico 5 apresenta a proporcionalidade entre as metodologias utilizadas nos artigos analisados neste estudo.

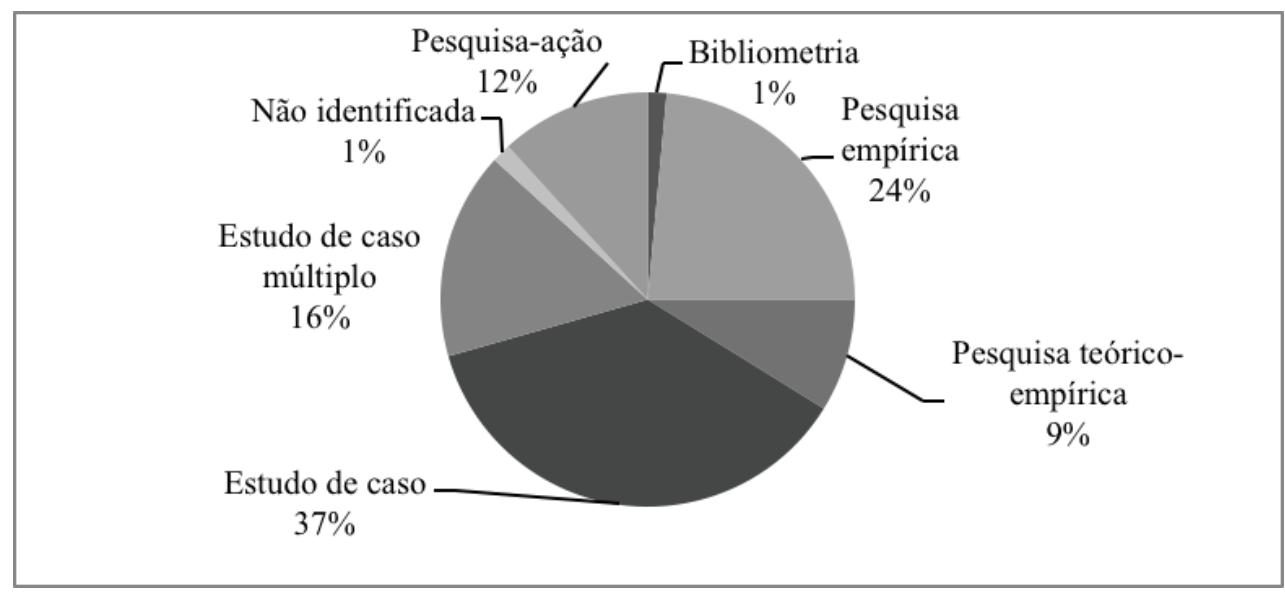

Gráfico 5 - Metodologias utilizadas nos estudos analisados

Fonte: dados da pesquisa.

Dos trabalhos analisados, extraíram-se, ainda, os objetivos de cada artigo, os quais foram, após a análise qualitativa, categorizados para que fosse possível sua mensuração. Verificou-se, assim, que a intenção de analisar a ferramenta BSC predominou nas pesquisas (45 trabalhos - quase $70 \%$ ), seguida do objetivo de descrever o processo de desenvolvimento e a implantação da ferramenta em organizações (oito artigos - 12\%). Na sequência, estão: análise da criação de valor após a implantação da ferramenta (cinco artigos, que representam pouco mais de 7\%), revisão conceitual do BSC na literatura nacional e internacional (com quatro trabalhos, que representam quase $6 \%$ ), medição do desempenho por meio da utilização da ferramenta (três trabalhos, cerca de $5 \%$ de representatividade) e análise da percepção dos usuários acerca do BSC, mapeamento de pesquisas sobre o tema e proposição de um mapa estratégico para a organização em análise (apenas um trabalho cada, os quais representam pouco mais de $1 \%$ ). O Gráfico 6 apresenta estes dados: 


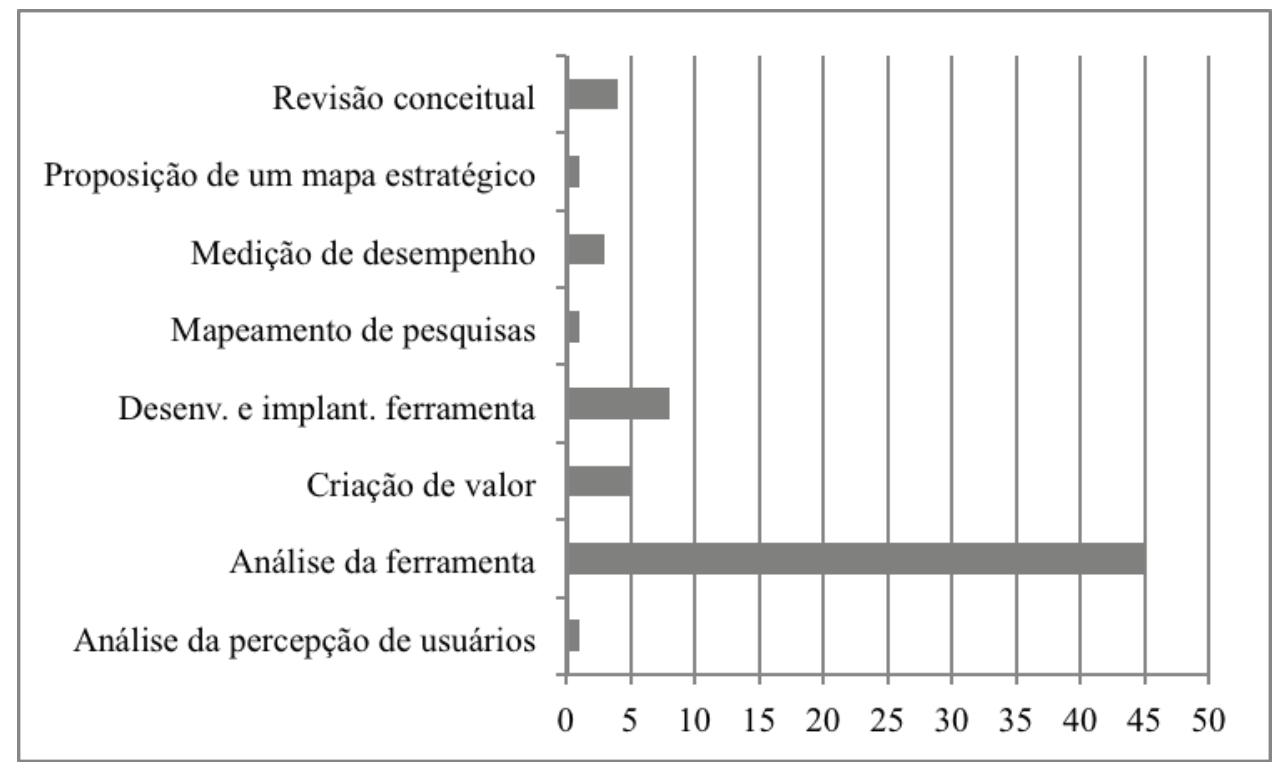

Gráfico 6 - Objetivos dos artigos analisados

Fonte: dados da pesquisa.

A análise qualitativa abrangeu, também, a verificação do modo como o BSC foi tratado em cada estudo, se como variável dependente ou independente. Os resultados mostraram que $74 \%$ dos estudos consideraram o BSC como variável dependente, ou seja, que pode(ria) ser influenciada no decorrer do estudo, uma vez que pesquisas que utilizaram a metodologia estudo de caso e pesquisa-ação configuram quase metade dos artigos analisados (49\%), metodologia esta que possibilitou a interação entre pesquisador e organização. Sousa (2005) afirma que variável dependente é aquela que depende da investigação, estando diretamente ligada ao resultado obtido com os procedimentos metodológicos.

Verificaram-se, também, as palavras-chave utilizadas para identificar os artigos e facilitar os mecanismos de busca. Destas, o termo mais utilizado foi o Balanced Scorecard ou BSC, que, do total de 143 palavras-chave analisadas, representa $26 \%$. Outras palavras/ termos que mais apareceram foram: Gestão $(8 \%$, considerando-se neste percentual os termos Gestão da Saúde, Gestão Estratégica, Gestão da Performance, Gestão de Pessoas, Gestão por
Competência, Gestão por Processos e Gerenciamento Contábil); Contabilidade Gerencial (5\%); e Mensuração de Desempenho (considerando-se também Medidas de Avaliação de Desempenho e Medição do Desempenho), Planejamento Estratégico e Instituições de Ensino Superior (3\% cada um). Ressaltase, ainda, que esse resultado não pode ser aplicado à totalidade dos artigos analisados por este estudo, visto que o número de palavras-chave por artigo não é padronizado e que, em algumas edições (tanto de congressos quanto de periódicos), estas não são informadas.

Para finalizar, verificou-se, ain$\mathrm{da}$, se os estudos analisados utilizavam alguma teoria como base para a condução de cada pesquisa. Desta análise, foi observado que apenas 9\% dos estudos utilizaram alguma teoria de base, tendo sido identificadas a Teoria das Representações Sociais, a Teoria das Restrições e a Teoria Institucional. Destes 9\% selecionados, o trabalho de Malacarne, Balassiano e Nossa (2011) afirma que a maneira que as pessoas reagem às pressões para o alcance das metas instituídas pelo BSC nas organizações ainda é pouco analisada pelas pesquisas e, por isso, os 
autores propuseram-se a avaliar e discutir a repercussão da ênfase nas questões objetivas no relacionamento da organização com seus empregados, utilizando as representações sociais das práticas de gestão de pessoas na discussão teórica. Os resultados mostraram implicações claras nas representações sociais das práticas de gestão de pessoas em decorrência da ênfase nas questões objetivas, de modo que o artigo contribuiu para a discriminação das variadas formas pelas quais se verificaram impactos entre os níveis hierárquicos da organização.

A Teoria das Restrições foi adotada por duas pesquisas: Rodrigues, Schuch e Pantaleão (2003) apresentam uma proposta teórica de integração entre os conceitos do Balanced Scorecard (dimensões não financeiras) e da Teoria das Restrições (indicadores globais), enquanto que Cevey e Rodrigues (2007) desenvolveram uma abordagem metodológica para a construção de um painel de controle executivo para empresas operadoras de planos de saúde, considerando os princípios do BSC e da Teoria das Restrições.

A Teoria Institucional foi utilizada por Santana e Colauto (2010) para identificar de que maneira se configuram os instrumentos empregados na prática da gestão em uma empresa brasileira atuante no setor elétrico de acordo com os estágios de institucionalização propostos por Tolbert e Zucker (1999). Os autores verificaram que o BSC se encontra no estágio de total institucionalização. Russo et al. (2012) propuseram-se a analisar a obra "A Estratégia em Ação - Balanced Scorecard", com base na Teoria Institucional, para verificar a existência de evidências de que o modelo do BSC proposto pelos autores Kaplan e Norton possui elementos que favoreçam a sua institucionalização. Os autores concluíram que a obra apresenta preocupação em legitimar a ferramenta junto às organizações por meio da apresentação desta como um instrumento consagrado de gestão. Outros aspectos da pesquisa possibilitam a conclusão de que os autores se propõem a propor uma ferramenta sem o foco efetivo em sua institucionalização, justificando, talvez, a dificuldade encontrada por empresas que investem na implantação dessa metodologia e não conseguem obter os resultados esperados deste processo.

\section{Considerações finais}

Dos resultados encontrados pelo presente estudo, é possível depreender que o BSC é um tema bastante pesquisado no universo acadêmico, sobretudo por meio de metodologias que instigam o estreitamento da relação entre academia e empresariado, como a pesquisa-ação e o estudo de caso. A representatividade dos trabalhos publicados em congressos em detrimento dos veiculados por periódicos pode ser entendida como incentivo à discussão sobre o assunto, uma vez que o congresso é um evento em que se reúnem diversos pesquisadores para debate dos assuntos ali expostos. Talvez uma justificativa para que o número de trabalhos apresentados em congressos $(60 \%)$ não se equipare ao número de artigos publicados em periódicos seja a possibilidade de publicação dos artigos apresentados em periódicos que não tenham sido analisados por este estudo, podendo este fato ser considerado como uma limitação do presente estudo e uma sugestão para futuros trabalhos que se dediquem a explorar esta temática. Dentre os congressos, o que apresentou maior representatividade na discussão do assunto foi o EnANPAD, enquanto que, dentre os periódicos, foi a Revista Universo Contábil.

Dos trabalhos analisados, foi possível verificar a centralidade de uma pesquisadora que apresentou quatro trabalhos publicados: Vera Maria Rodrigues Ponte. Em contrapartida, 103 dos 135 pesquisadores levantados na pesquisa publicaram apenas um trabalho sobre o assunto, o que remete ao fato de que estes podem não ser con- 
siderados como especialistas, já que suas produções se mostraram pontuais. Diante disso, confirma-se o efeito Mateus, de modo que poucos publicam muito e muitos publicam pouco sobre determinado assunto, o que não implica o aprofundamento pelo(s) autor(es). Limitação deste estudo é ter se centrado na análise de somente alguns congressos e periódicos, ao invés da análise da totalidade dos meios de publicação, em virtude do tempo e da disponibilidade dos autores.

A metodologia de pesquisa que mais foi verificada nos artigos foi o estudo de caso (37\%), tendo sido verificados também a pesquisa empírica, o estudo de caso múltiplo, a pesquisa-ação, a pesquisa teórico-empírica e a bibliometria. Desse resultado, é possível concluir que métodos que impliquem a relação direta entre pesquisador e empresa predominam, isto é, o BSC é estudado, na maioria das vezes, por meio do processo de interação entre pesquisador e empresariado e, em alguns casos, por meio do desenvolvimento da ferramenta para a organização e por meio da análise dos resultados obtidos (ou não) depois da implantação da metodologia. Confirma este achado o fato de que quase $70 \%$ dos artigos analisados tinham como objetivo analisar a ferramenta BSC e outros $12 \%$ se propuseram a descrever o processo de desenvolvimento e implantação da ferramenta em organizações. De modo complementar, a utilização do BSC como variável dependente por $74 \%$ das pesquisas corrobora tais resultados no que se refere ao estreitamento da relação entre academia e empresariado.

Não foi possível confirmar a hipótese, analisando-os os artigos levantados quanto aos motivos que levaram as organizações a adotar a ferramenta e à maneira como isso ocorreu, bem como o período em que se deu, de que existe um modismo gerencial, devido à falta de aprofundamento dos trabalhos analisados, que se resumiram a descrever superficialmente seus achados. Talvez, tal resultado já pudesse ter sido esperado em função da restrição de páginas, por exemplo, que é imposta aos pesquisadores quando decidem publicar seus trabalhos nos meios científicos.

No que se refere à utilização de alguma teoria de base para a condução das pesquisas, verificou-se que apenas 9\% utilizaram alguma teoria (Teoria das Representações Sociais, Teoria das Restrições e Teoria Institucional). Os demais trabalhos foram estruturados, basicamente, sobre os conceitos do BSC sem a sustentação de qualquer teoria, o que denota que estudos estão sendo conduzidos sem o direcionamento teórico de teorias nos campos da Administração, Ciências Contábeis ou Economia.

As notórias contribuições desta pesquisa para a academia estão no fato de ter verificado a pluralidade de objetivos de estudos relacionados à ferramenta BSC, explorando, sobremaneira, o conjunto de informações levantado por meio desta pesquisa, especialmente quanto aos aspectos quantitativos. Portanto, apresenta-se como sendo de relevância para o meio acadêmico por analisar a representatividade dos trabalhos publicados nacionalmente, incentivando, assim, uma maior discussão sobre o assunto neste meio. Já o empresariado se beneficia desta pesquisa na medida em que pode utilizá-la como balizador para o estudo e a exploração de relatos e pesquisas que já tenham sido realizadas pelo meio acadêmico, estreitando, dessa forma, o gap existente entre estes meios.

Tendo em vista as limitações desta pesquisa, sugere-se a análise de um número maior de congressos e periódicos, tanto nacionais quanto internacionais, o que possibilitaria traçar um panorama da pesquisa nestas duas dimensões - nacional e internacional. 


\section{Referências}

1. ALMEIDA, S.; MARÇAL, R.F.M.; KOVALESKI, J.L. Metodologias para a avaliação de desempenho organizacional. In: ENCONTRO NACIONAL DE ENGENHARIA DE PRODUÇÃO, 24., 2004, Florianópolis. Anais... Florianópolis: ENEGEP, 2004.

2. ATTADIA, L.C.L.; CANEVAROLO, M.E.; MARTINS, R.A.M. Balanced Scorecard: Uma Análise Crítica. In: ENCONTRO NACIONAL DE ENGENHARIA DE PRODUÇÃO, 23., 2003, Ouro Preto. Anais... Ouro Preto: ENEGEP, 2003.

3. BANKER, R.D; POTTER, G; SRINIVASAN, D. An empirical investigation of an incentive plan that includes nonfinancial performance measures. The Accounting Review, Florida, v. 75, n. 1, p. 65-92, jan, 2000.

4. CATAPAN, A.; CARON, T.A.; OGATA, C.R.D.; CAMARGO, T.M.; OLIVEIRA, S.C.K. Balanced Scorecard: Uma Análise Bibliométrica dos Anos de 2001 à 2011. In: CONGRESSO VIRTUAL BRASILEIRO DE ADMINISTRAÇÃO, 9., 2012, Manaus. Anais... Manaus: CONVIBRA, 2012.

5. CEVEY, M.J.; RODRIGUES, L.H. Desenvolvimento de uma abordagem metodológica para construção de painel de controle executivo, utilizando os conceitos do balanced scorecard e a sistemática de indicadores da teoria das restrições: uma aplicação para atividade de operadoras de planos de saúde. In: CONGRESSO DA ASSOCIAÇÃO NACIONAL DOS PROGRAMAS DE PÓS-GRADUAÇÃO EM CIÊNCIAS CONTÁBEIS, 1., 2007, Gramado. Anais... Gramado: ANPCONT, 2007.

6. COAD, A.F. Some survey evidence on the learning and performance orientations of management accountants. Management Accounting Research, n. 10, p. 109-135, 1999.
7. GOMES, J.S.; SALAS, J.M.A. Controle de Gestão: uma abordagem contextual e organizacional. 3. ed. São Paulo: Atlas, 2001.

8. HEINRICH C. J. Como avaliar o desempenho e a efetividade do setor público. In. PETERS, G.; PIERRE, J. Administração Pública: Coletânea. ENAP, Editora Unesp. 2010.

9. KALLÁS, D. Balanced Scorecard: aplicação e impactos. Um estudo com jogos de empresas. 2003. Dissertação (Mestrado em Administração) - Faculdade de Economia, Administração e Contabilidade (FEA), Universidade de São Paulo (USP), São Paulo.

10. KAPLAN, R.S. The balanced scorecard: comments on balanced scorecard commentaries. Journal of Accounting \& Organizational Change. v. 8, n. 4, p. 539-545, 2012.

11. KAPLAN, R.S.; NORTON, D.P. Organização Orientada para a Estratégia: Como as empresas adotam o Balanced Scorecard no novo ambiente de negócios. Rio de Janeiro: Campus, 2000.

12. KAPLAN, R.S.; NORTON, D.P. A estratégia em ação: Balanced Scorecard. Rio de Janeiro: Elsevier, 1997.

13. MACHADO-DA-SILVA, C.L.; FONSECA, V.S.; FERNANDES, B.H.R. Mudança e estratégia nas organizações: perspectivas cognitiva e institucional. In: VIEIRA, M. M. F.; OLIVEIRA, L. M. B. (Orgs.). Administração contemporânea: perspectivas estratégicas. São Paulo: Atlas, 1999.

14. MALACARNE, R.; BALASSIANO, M.; NOSSA, V. Implicações do BSC nas representações sociais das práticas de gestão de pessoas: estudo de caso em uma instituição de educação profissional. In: CONGRESSO DA ASSOCIAÇÃO NACIONAL DOS PROGRAMAS DE PÓS-GRADUAÇÃO EM CIÊNCIAS CONTÁBEIS, 5., 2011, Vitória. Anais... Vitória: ANP- 
CONT, 2011.

15. MARTINO, J. P. Technological forecasting for decision making. 3 . ed. New York: Mc Graw-Hill Inc., 1993.

16. MERTON, R. K. The Mathew effect in science. Science, v. 159 , n. 3810, p. 58, jan. 1968.

17. NEELY, A.; MILLS, J.; PLATTS, K.; GREGORY, M.; RICHARDS, H. Performance Measurement System Design: should Process Basead Approaches be adopted? International Journal Production Economics, Amsterdam, v. 46-47, p. 423-431, 1996.

18. OKUBO, Y. Bibliometric indicators and analysis of research systems: methods and examples. OECD Science, Technology and Industry Working Papers, 1997/1, OECD Publishing, 1997.

19. OLIVEIRA, W.R.; MARTINS, S.; OLIVEIRA; A.C.P.; PINTO, T.R.G.S. Análise do Processo de institucionalização do Balanced Scorecard no Instituto Nacional do Seguro Social. In: CONGRESSO UFV DE ADMINISTRAÇÃO E CONTABILIDADE, 5., 2012, Viçosa. Anais...Viçosa: UFV, 2012.

20. OLVE, N.G.; ROY, J.; WETTER, $M$. Condutores da Performance: Um guia prático para o uso do "Balanced Scorecard". Rio de Janeiro: Qualitymark, 2001.

21. PICOLI, F.R.; ABIB, G.; FONSECA, M.W. Balanced Scorecard: um estudo bibliométrico acerca da produção acadêmica da década de 2001-2011 no Brasil. Revista de Contabilidade e Controladoria, v. 4, n. 3, p. 128-142, set./dez. 2012.

22. RODRIGUES, L.H.; SCHUCH, C.; PANTALEÃO, H. Uma Abordagem para Construção de Sistemas de Indicadores Alinhando a Teoria das Restrições e o Balanced Scorecard. In: ENCONTRO NACIONAL DA ASSOCIAÇÃO NACIONAL DE PÓS-GRADUAÇÃO EM ADMINISTRAÇÃO, 2003, Ati- baia. Anais... Atibaia: ENANPAD, 2003.

23. RUSSO, P.T.; PARISI, C.; MEGLIORINI, E.; ALMEIDA, C.B. Evidências de elementos de institucionalização do Balanced Scorecard na obra "A estratégia em ação": um olhar baseado na teoria institucional. Revista Contabilidade e Finanças, v. 23, n. 58, p. 7-18, jan./fev./mar./abr. 2012.

24.SALES, J.D.A.; SILVA, P.K. Os fatores de resistência a mudança organizacional e suas possíveis resultantes positivas: um estudo de caso na Indústria Calçados Bibi do Município de Cruz das Almas - BA. In: SEMINÁRIO EM ADMINISTRAÇÃO FEA-USP, 10., 2007, São Paulo. Anais... São Paulo: SEMEAD, 2007.

25. SANTANA, G.A.S. Institucionalização de Instrumentos Gerenciais: $\mathrm{O}$ caso de uma organização do setor elétrico. 2010. Dissertação (Mestrado em Ciências Contábeis) - Faculdade de Ciências Econômicas, Universidade Federal de Minas Gerais (UFMG), Belo Horizonte.

26. SANTANA, G.A.S.; COLAUTO, R.D. Institucionalização de Instrumentos Gerenciais: o caso de uma organização do setor elétrico. In: ENCONTRO NACIONAL DA ASSOCIAÇÃO NACIONAL DE PÓS-GRADUAÇÃO EM ADMINISTRAÇÃO, 34., 2010, Rio de Janeiro. Anais... Rio de Janeiro: ENANPAD, 2010.

27. SOUSA, A. B. Investigação em educação. Lisboa: Livros Horizonte, 2005.

28. TAGUE-SUTCLIFFE, J. An introduction to informetrics. Information Processing \& Management, v. 28, n. 1, p. 1-3, 1992.

29. THIOLLENT, M. Metodologia da Pesquisa-Ação nas Organizações. São Paulo: Ed. Cortez, 1997.

30. TOLBERT, P.S.; ZUCKER, L.G. A institucionalização da teoria insti- 
tucional. In: CLEGG, S.R.; HARDY, C.; NORD, W.R. (org.). CALDAS, M.; FACCHIN, R.; FISCHER, T. (org. brasileiros). Handbook de estudos organizacionais, modelos de análise e novas questões em estudos organizacionais. v. 1. São Paulo: Atlas, 1999.

31. VEEN-DIRKS, P.. Different uses of performance measures: The evaluation versus reward of production managers. Accounting, Organizations and Society, 35, 2010, p. 141-164. 